\title{
Transmission Planning Studies for the Renewable Energy Zone (REZ) Process
}

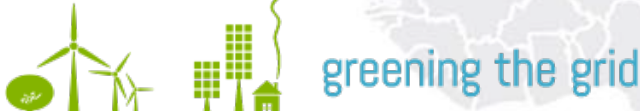

I

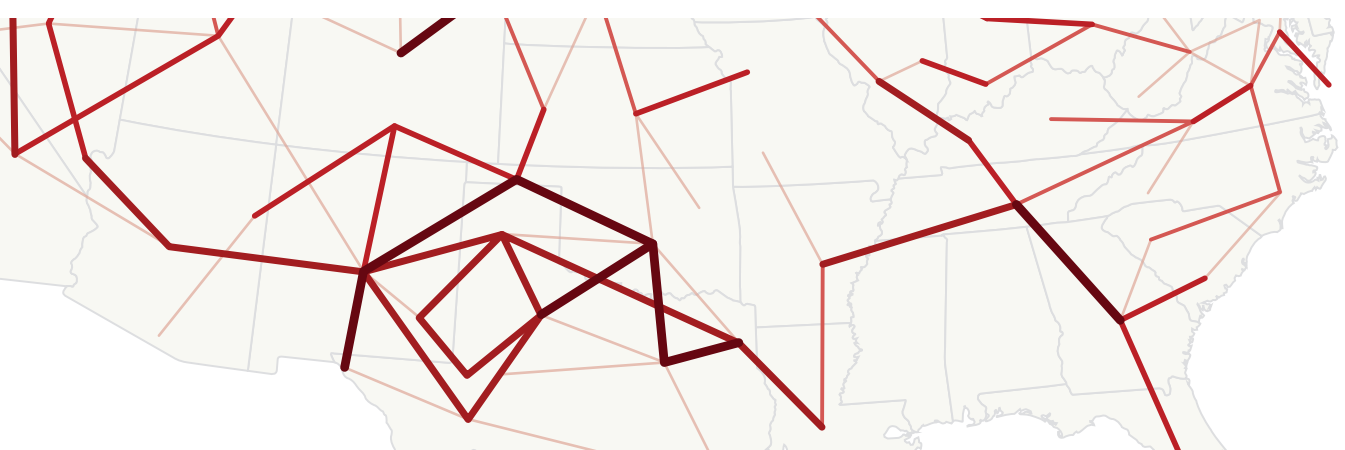

Hours of Transmission Congestion

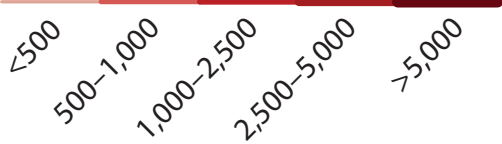

Transmission planning studies provide the information power system planners need to select transmission enhancements that will help reliably and economically connect renewable energy zones (REZs) to load. For example, the map above of potential transmission options in the southern United States for the year 2050 shows the hours per year of congestion that transmission lines may experience based on future demand and generation forecasts [1]. Transmission congestion occurs when the lines that connect two areas reach their power-flow capacity. Such congestion can impact the reliability and economics of the power system. By examining transmission expansion options, planners can provide for future load, maintain reliability, and avoid congestion that can lead to curtailment of renewables and operation of expensive generation. This document provides an overview of the analyses planners use to study transmission upgrade and expansion options as well as the associated modeling considerations-including data requirements-for Step 4 of the REZ process, which addresses the development of transmission options.

\section{HOW CAN WE SUPPLY LOAD WITH RENEWABLE ENERGY?}

Transmission planning studies help power system planners determine how they can best supply load with renewable energy.

The early steps of the REZ process result in the identification of multiple candidate REZs. Many potentially feasible transmission expansion and upgrade options may exist to deliver the electricity from these zones to load. Knowledge of the location and target installed capacity of each candidate REZ allows power system planners to conduct transmission planning studies that identify the costs, benefits, and reliability impacts associated with various transmission line additions, equipment upgrades, and new substations and transformers. Furthermore, such studies help identify the lowest-cost, preferred transmission enhancement (upgrade and/or expansion) option that meets reliability and other system requirements.

The transmission enhancement options may bundle different combinations of candidate REZs and, as a result, each option could transfer a different total amount of power (megawatts) from new renewable energy generators to the grid. For example, one option may connect all candidate zones to load while a second option may connect only a few candidate REZs with less attractive renewable energy potential. Options may also represent different approaches to connecting zones to the existing system, including alternative network topologies (e.g., hub-and-spoke circuits in zones or loop circuits around zones), modifications of line voltage levels (e.g., refurbishing lines), or combinations of high voltage direct-current (HVDC) or alternating-current $(\mathrm{AC})$ lines, among other approaches.

Transmission system operators, utilities, and regulatory authorities commonly have power system-specific requirements and processes in place for these planning studies. The general approach presented in the following sections is broadly based on the Texas Competitive Renewable Energy Zones (CREZ) initiative [3].

\section{DO TRANSMISSION EXPANSION OPTIONS MEET ECONOMIC, RELIABILITY, OR OTHER OBJECTIVES?}

Transmission planning studies — which often consist of the three types of analyses shown in Figure 1-help system planners identify transmission expansion options that meet their objectives.

\section{The REZ Transmission Planning Process}

The renewable energy zone (REZ) transmission planning process is an approach to connect areas with concentrated renewable energy resources to the power grid. The process helps to plan, approve, and build transmission infrastructure to access areas with high-quality resources, suitable topography and land-use designations, and demonstrated developer interest-supporting reliable and economic integration of renewable energy.

\section{Step 1. Process Design \& Vision Statement}

Step 2. Renewable Energy Resource Assessment

Step 3. Candidate Zones Selection

Step 4. Transmission Options Development

Step 5. Final Transmission Plan Designation

Step 6. Transmission System Upgrade

The Renewable Energy Zone (REZ) Transmission Planning Process: A Guidebook for Practitioners details each step of the REZ process from setting a vision through to final transmission system upgrades [2]. 


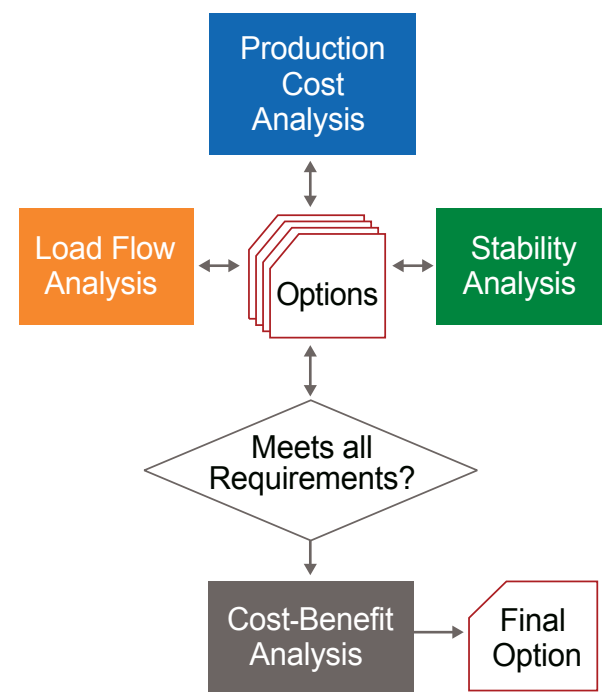

Figure 1. Example Transmission Planning Study analyses

Production cost analyses help planners understand the operational cost and performance of transmission expansion options and prioritize project options. And, load-flow and stability analyses help planners ensure the feasibility and reliability of the transmission system and refine cost estimates. Such studies only address operational costs, and they do not capture the often-significant capital costs of transmission expansion. The overall aim of such studies, which are outlined in Table 1 and further described in the next sections, is to identify solutions that can be used to address any deficiencies before proceeding to a cost-benefit analysis of the acceptable options that considers capital and operational costs.

The three specific main goals to conducting each analysis are:

1. Assess whether an option is technically feasible from a reliability perspective

2. Identify necessary refinements to meet reliability goals

3. Understand how these refinements may influence the production costs.

Each analysis is iterative, with any potential limitations or improvements driving revisions to the options, which are then reanalyzed. Options may begin as coarse depictions of potentially feasible solutions, with clarity added as they are revised and advanced through the analyses. The final output is a refined set of feasible options that include the location and design parameters of new transmission lines and other improvements such as new substations, transformers, or other devices. Options that were initially unattractive may become prominent after these analyses, as some options may be found to have significant limitations.

\section{Operational Costs and Impacts}

Production cost analysis is the principal approach used to quantify operational cost changes related to transmission expansion options, not accounting for capital cost. Production cost analysis simulates bulk power system scheduling, which is generally performed by solving a unit commitment and economic dispatch problem, subject to constraints. Solving this problem determines the least-cost combination of online units (unit commitment) and their exact power output (economic dispatch) scheduled to meet total demand, subject to system physical constraints (e.g., load balance, power flow laws, and generator capabilities) and security constraints (e.g., transmission limitations, contingency reserves, and single or multiple element failure contingencies). Modern production cost modeling tools can co-optimize energy as well as operating reserve products such as contingency, regulating, and/or flexibility reserves for the power system.

Production cost simulations typically consider a one-year planning horizon with chronological hourly or subhourly temporal resolution. Simulation along this horizon provides a clear understanding of system operation under potentially significant seasonal variations in both renewable energy resource availability and load. Simulating all probable operating conditions for multiple years is impractical because of the computing power and time needed.

The key outputs of a production cost modeling simulation are the detailed time series and annual, aggregated results for power generation from generating units and the associated costs of system operation. Additional outputs include transmission system congestion, renewable energy curtailment, congestion costs, reserve holding and shortage, unserved energy, and locational marginal prices of electricity. Production cost models approximate AC flow for simplification and computational feasibility; therefore, additional modeling is needed to evaluate the reliability of the options. For more information on production cost models and associated data requirements see $[4,5]$.

\section{GLOSSARY}

Adequacy: The ability of the electric system to meet demand and energy requirements at all times, taking into account scheduled and reasonably expected unscheduled outages of system elements.

Congestion: Occurs when transmission system constraints reduce transmission flows and the lowest-cost electricity cannot be delivered to demand requiring the system to rely on higher-cost generation sources; in addition to impacting costs, congestion can cause reliability issues if constraints limit access to reserves.

Contingency: The unexpected failure or outage of a system component, such as a generator, transmission line, circuit breaker, switch, or other electrical element.

Cost-benefit analysis: Compares the capital costs and expected benefits of a plan and is typically evaluated as a ratio with the total benefits as the numerator and the total costs of the plan (in net present value) as the denominator.

Curtailment: A reduction in the output of a variable renewable energy generator from what could be produced given available resources.

Economic dispatch: The allocation of demand to individual online generating units to affect the most economical production of electricity.

Load: Aggregated customers that receive power from the electric system or the total demand (MW) of these customers.

Load flow (power flow) analysis: Examines the steady-state (after dynamic behavior of the system settles) operation of the transmission system at an instant in time to ensure operational feasibility and adequacy to meet load and accounts for scheduled and reasonably expected, unscheduled generator outages.

Locational marginal price: The marketclearing price for electricity at the location the energy is delivered or received.

Production cost analysis: A tool to optimize the scheduling of load and generation resources to meet expected demand over various timeframes with consideration of cost and constraints (e.g., system, physical, operational); production cost analysis is the leading tool to evaluate the impacts of variable renewable power on the operational costs of a system.

Reserves: Generators that are available to a system operator to provide for regulation (i.e., response to random movements during normal conditions), load forecasting error, forced and scheduled equipment outages, and local area protection; reserves include contingency (deployed in response to generator failures), regulating (secondary frequency response via automatic generation control), or flexibility (reserves to address variability and uncertainty on timescales longer than regulating reserves). 


\section{Reliability During Critical Periods} Load flow (also referred to as power flow) analysis provides a snapshot of the transmission system that allows planners to identify the limitations of and/or needs for system reliability and test potential solutions to ensure voltage levels and other characteristics remain within acceptable system conditions. Load flow analysis simulates steadystate AC power flow of the transmission system, including voltage levels and phase angles at substation buses, active and reactive power flows in transmission branches, and system losses. This type of modeling helps ensure operational feasibility of the system at nominal conditions and adequacy of the system to meet load, accounting for scheduled outages and reasonably expected unscheduled outages [6].

A load flow analysis is conducted for select periods (i.e., seconds to minutes), as a simulation of all possible operating points throughout a year is not computationally feasible. The load flow analysis can use the commitment and dispatch outputs of the production cost analysis to identify critical periods of the year that may affect system reliability. Select periods depend on study requirements but typically focus on periods when power systems may experience extremes such as peak load, minimum load, maximum power transfer across transmission interfaces, or periods of low or high renewable energy generation. A load flow analysis helps planners ensure the system can maintain reliability through these critical periods.

\section{Stability and Recovery from Contingencies}

Transient and dynamic-stability analyses simulate the dynamic performance of the power system, which depict the system's ability to withstand an unexpected disturbance and recover back to stable, steadystate operation. A depiction of the dynamic performance of the system helps ensure it is sufficiently planned to recover to a steady state after an outage or other disturbance without causing additional disturbances or requiring significant modifications outside nominal operating capacity of the system [3]. This information helps planners further understand the reliability limitations and contingency needs of transmission expansion options.

Stability analyses may use the outputs and knowledge obtained from production cost and load flow analyses to set initial, steady-state conditions. These simulations then examine various stability concerns, including the voltage and transient stability after a transmission fault, frequency stability following sudden loss of generation or load shedding, and ability to maintain synchronization after smallsignal disturbances. They look at whether a system can recover and avoid a partial system collapse. The complexity of these analyses rises quickly with increases in the number of elements on the system, contingency events, or scenarios considered. To limit complexity, the events are constrained to the most common and severe events that a system may realistically face, and the analysis is typically conducted for short periods - on the order of subseconds to minutes [7].

\section{WHAT SOFTWARE TOOLS ARE NEEDED?}

Power systems are an assembly of familiar interconnected elements (e.g., load, generators, transmission lines, and transformers); however, the interconnection of these elements and each of their individual characteristics results in a complex system. Power system analyses employ models that simplify these complex systems, examine performance on different time scales, and rely on imperfect knowledge of the futureincluding fuel prices, regulations, generation expansion, and demand increases. For this reason, no single modeling activity can capture and solve an entire transmission expansion problem. Instead, several distinct modeling exercises are conducted to understand system behavior, model limitations, and the effects of these limitations. The benefits of these exercises come from comparing several options - not a single solution-and exploring sensitivities and trends. Finally, it is helpful to assess all these results collectively and with broader contextual knowledge [8].

The tools used for transmission planning studies require expert users and good data to ensure well-informed decision-making. The best data and the perfect model are often not available, and planners may have to advance with the what is available to obtain initial results and identify priority data needs to improve models. Several tools are available for production cost, steadystate, and dynamic stability analyses from private vendors, and the unique needs and context of the user will determine which is the appropriate tool for each application.

\section{GLOSSARY}

Scheduling: The practice of ensuring a generator is committed and available when needed.

Stability analysis: Simulation of the grid under a range of dynamic events to evaluate: frequency stability after a generation and load imbalance; voltage stability after a disturbance; transient stability to maintain generator synchronism after a disturbance; and small-signal stability to maintain steadystate conditions of voltage, current, and power magnitudes after a small disturbance.

Substation buses: An electrical junction point where two or more transmission elements are connected.

Unit commitment: Scheduling of the online and offline status of generators, considering the processes required for generators to start up and shut down.

\section{WHICH TRANSMISSION EXPANSION OPTION IS MOST ATTRACTIVE?}

Transmission planning studies help decision makers narrow the list of attractive transmission enhancement options that connect REZs to load. Planners can use the results of these studies to assess the value of proposed transmission system enhancements, once initial capital costs are considered. A cost-benefit analysis is a common approach to comparing the expected costs to the benefits that can be attributed to a project. The costs and benefits are expressed in monetary units, and the results are presented as a benefitto-cost ratio, which has a value greater than one (1) where the expected benefits exceed costs. Costs may include capital costs of assets, cost of rights-of-way, construction costs, and the cost of financing. A broad set of benefits can be considered, and they commonly include production cost savings, reliability benefits, generation capacity cost savings, and local and global environmental impact reductions. Additional criteria such as legislative intent to develop clean energy, future expansion capability, or other social, environmental, or economic criteria can also be considered [9].

Designation of a final transmission plan may also hinge on additional reliability and ancillary-cost analyses to ensure all relevant regulatory authority requirements for issuing a final transmission order are met. 
Table 1. Overview of Transmission Planning Study Analyses

\begin{tabular}{|c|c|c|c|}
\hline & Production Cost Analysis & Load Flow Analysis & Stability Analysis \\
\hline Purpose & $\begin{array}{l}\text { Estimate operational cost and } \\
\text { performance impacts on the power } \\
\text { system that result from transmission } \\
\text { expansion options }\end{array}$ & $\begin{array}{l}\text { Identify limitations of system operational } \\
\text { feasibility and reliability given scheduled } \\
\text { and reasonably expected, unscheduled } \\
\text { outages; refine cost estimates }\end{array}$ & $\begin{array}{l}\text { Identify reliability limitations and contin- } \\
\text { gency needs of the transmission system } \\
\text { to withstand unexpected disturbances and } \\
\text { recover to steady state; refine cost estimates }\end{array}$ \\
\hline Inputs & $\begin{array}{l}\text { Detailed data on: } \\
\text { - Generator parameters } \\
\text { - Storage parameters } \\
\text { - Load (profile and forecast) } \\
\text { - Transmission parameters } \\
\text { - Substation bus parameters } \\
\text { - Electricity market details } \\
\text { - Energy or fuel resources } \\
\text { - Time-synchronous generation and } \\
\text { load data }\end{array}$ & $\begin{array}{l}\text { Detailed data on: } \\
\text { - Generator and storage commitment and } \\
\text { dispatch for periods of interest } \\
\text { - Contingency events } \\
\text { - Load } \\
\text { - Transmission parameters } \\
\text { - Substation bus parameters }\end{array}$ & $\begin{array}{l}\text { Detailed data on: } \\
\text { - Generator dynamic models } \\
\text { - Inverter control models } \\
\text { - Contingency event list } \\
\text { - Load } \\
\text { - Transmission parameters } \\
\text { - Substation bus parameters }\end{array}$ \\
\hline Outputs & $\begin{array}{l}\text { Detailed data on: } \\
\text { - Generation } \\
\text { - Operational costs } \\
\text { - Electricity prices } \\
\text { - Transmission system congestion } \\
\text { - Expected renewable energy curtailment } \\
\text { - Reserve holding } \\
\text { - Lost load probability } \\
\text { - Emissions }\end{array}$ & $\begin{array}{l}\text { Detailed data on: } \\
\text { - Voltage levels and phase angles at } \\
\text { buses } \\
\text { - Active and reactive power flows in } \\
\text { transmission lines } \\
\text { - System losses }\end{array}$ & $\begin{array}{l}\text { Detailed data on the dynamic performance } \\
\text { of the system in the seconds after simulated } \\
\text { faults: } \\
\text { - Rotor angle stability } \\
\text { - Frequency stability } \\
\text { - Voltage stability }\end{array}$ \\
\hline $\begin{array}{l}\text { Key institutions } \\
\text { that may } \\
\text { perform or } \\
\text { contribute to } \\
\text { the analysis }\end{array}$ & $\begin{array}{l}\text { - Ministries of energy } \\
\text { - Regulators } \\
\text { - System operators or planners } \\
\text { - Utilities } \\
\text { - Research institutes or consultants }\end{array}$ & $\begin{array}{l}\text { - Regulators } \\
\text { - System operators or planners } \\
\text { - Utilities } \\
\text { - Research institutes or consultants }\end{array}$ & $\begin{array}{l}\text { - Regulators } \\
\text { - System operators or planners } \\
\text { - Utilities } \\
\text { - Research institutes or consultants }\end{array}$ \\
\hline
\end{tabular}

\section{REFERENCES}

[1] Mai, Treui, Ryan Wiser, Debbie Sandor, Greg Brinkman, Garvin Heath, Paul Denholm, Donna J. Hostick, et al., Exploration of High-Penetration Renewable Electricity Futures: Vol. 1 of Renewable Electricity Futures Study (Golden, CO: National Renewable Energy Laboratory, 2012), NREL/ TP-6A20-52409-1. https://doi.org/10.7799/1255077.

[2] Lee, Nathan, Francisco Flores-Espino, and David Hurlbut, Renewable Energy Zone (REZ) Transmission Planning Process: A Guidebook for Practitioners (Golden, CO: National Renewable Energy Laboratory, 2017), NREL/TP-7A40-69043. www.nrel.gov/docs/ fy 17 osti/69043.pdf.

[3] ERCOT, Competitive Renewable Energy Zones (CREZ) Transmission Optimization Study: Attachment $A$ (Austin, TZ: Electric Reliability Council of Texas, 2008). http://www.ercot.com/content/news/presentations/2008/ERCOT_Website_Posting.zip.
[4] Katz, Jessica, Grid Integration Studies: Data Requirements, Greening the Grid (Golden, CO: National Renewable Energy Laboratory, 2015), NREL/FS-6A20-63043. http://www.nrel.gov/docs fy15osti/63043.pdf.

[5] Katz, Jessica, and Ilya Chernyakhovskiy, Grid Integration Studies: Advancing Clean Energy Planning and Deployment. Greening the Grid (Golden, CO: National Renewable Energy Laboratory, 2016), NREL/TP-6A20-66504. https:/www.nrel.gov/ docs/fy16osti/66504.pdf.

[6] Arillaga, Jos, and Bruce Smith, Power and Energy: $A C-D C$ Power System Analysis (Stevenage, England: IET, 1997).

[7] Milligan, Michael, Erik Ela, Jeff Hein, Thomas Schneider, Gregory Brinkman, and Paul Denholm, Renewable Electricity Futures Study. Volume 4: Bulk Electric Power Systems: Operations and Transmission
Planning (Golden, CO: National Renewable Energy Laboratory, 2012), NREL/TP-6A20-52409-4. https:/ www.nrel.gov/docs/fy12osti/52409-4.pdf.

[8] Donohoo, Pearl, and Michael Milligan, Capricious Cables: Understanding the Key Concepts in Transmission Expansion Planning and Its Models (Golden, CO: National Renewable Energy Laboratory, 2014), NREL/TP-5D00-61680. https://www.nrel.gov/ docs/fy14osti/61680.pdf.

[9] O’Neill, Barbara, David Hurlbut, Ivonne Pena, Douglas Gagne, Cook Jeff, and Ricardo Bracho, Mexico's Regulatory Engagement in Bulk Electric Power System Planning:An Overview of U.S. Practices and Tools (Golden, CO: National Renewable Energy Laboratory, 2016), NREL/TP-5D00-66103. https://www.nrel.gov/docs/fy16osti/66103.pdf.

\section{Written by Nathan Lee and Clayton Barrows, National Renewable Energy Laboratory}

The REZ Toolkit is a collection of resources to help power system planners, developers, key decision makers, and stakeholders understand and use the REZ transmission planning process to integrate transmission expansion planning and renewable energy generation planning. For more information:

Jennifer E. Leisch, Ph.D.

USAID-NREL Partnership Manager

U.S. Agency for International Development

Tel: +1-303-913-0103

Email: jleisch@usaid.gov

The REZ Toolkit is part of the Greening the Grid technical platform, which addresses the technical challenges around grid modernization and state-of-the-art practices in bringing advanced energy technologies into the power sector. Greening the Grid is supported by the U.S. Agency for International Development.

NREL/TP-7A40-71005 • August 2018
Nathan Lee, Ph.D.

National Renewable Energy Laboratory

Tel: +1-303-384-7241

Email: nathan.lee@nrel.gov

\section{USAID RNREL}

greeningthegrid.org

nrel.gov/usaid-partnership

This work was authored, in part, by the National Renewable Energy Laboratory, operated by Alliance for Sustainable Energy, LLC, for the U.S. Department of Energy (DOE) under Contract No. DE-AC36-08GO28308. Funding provided by the United States Agency for International Development (USAID) under Contract No. IAG-17-2050. The views expressed in this publication do not necessarily represent the views of the DOE or the U.S. Government including USAID. 